\title{
A research on the vertical migration process and background value of cyanide in Jiaozhou Bay
}
Dongfang Yang ${ }^{1,2,4, a}$, Danfeng Yang ${ }^{3}$, Sixi Zhu ${ }^{1,2}$, Yunjie $\mathrm{Wu}^{1,2}$ and Fengyou Wang $^{1,2, b}$

${ }^{1}$ Research Center for Karst Wetland Ecology, Guizhou Minzu University, Guizhou Guiyang, China

${ }^{2}$ College of Chemistry and Environmental Science, Guizhou Minzu University, Guiyang, 550025, China

${ }^{3}$ College of Information Science and Engineering, Fudan University, Shanghai, 200433, China

${ }^{4}$ North China Sea Environmental Monitoring Center, SOA, Qingdao 266033, China.

adfyang_dfyang@126.com; 'bCorresponding author:wangfy2001@yahoo.com.cn

Keywords: Cyanide; Vertical distribution; Process; Background value; Jiaozhou Bay.

\begin{abstract}
We analyzed the seasonal variation, horizontal distribution, vertical distribution and background value of cyanide in the bay mouth of Jiaozhou Bay in 1983. Cyanide contents in the bay mouth were changing a lot by means of vertical water's effect. Cyanide contents in both surface and bottom waters were in orders of summer $>$ autumn $>$ spring. At spatial scale, the horizontal distributions of cyanide in different seasons were consistent, and were decreasing from the inside of the bay mouth to the bay mouth and then the ouside of the bay mouth. At variation scale, the variation ranges of cyanide contents in boto surface and bottom waters were consistent. At vertical scale, the horizontal distributions of cyanide in surface and bottom waters were consistent in case of high cyanide contents, yet were closed in case of low cyanide contents. At region scale, the differences of cyanide contents in surface and bottom waters were determined bay the inputs of cyanide. The seasonal variations and spatial distributions of cyanide were revealing the horizontal water's effect and vertical water's effect. The background values of cyanide in the bay were $0.02-0.22 \mu \mathrm{g} \mathrm{L}{ }^{-1}$.
\end{abstract}

\section{Introduction}

Cyanide used to be rare in water environmental until the rapid increasing of the pollution from human activities. Due to the high toxicity of cyanide, the pollution in the environment in the environmental would be harmful to human beings finally. The pollutants inputted to the maine bay have been increasing along with the rapid development of industrialization and urbanization, and the research on the seasonal variations and spatial distributions of cyanide is necessary [1-2]. Jiaozhou Bay is a semi-closed bay located in Shandong Province, eastern China. Due to the rapid development of industrialization and urbanization, this bay had been polluted by various pollutants including cyanide [1-2]. Based on investigation data on cyanide in waters in Jiaozhou Bay in 1983, this paper analyzed the spatial distributions and seasonal variations of cyanide, and revealed the migration processes and background values.

\section{Materials and method}

Jiaozhou Bay $\left(35^{\circ} 55^{\prime}-36^{\circ} 18^{\prime} \mathrm{N}, 120^{\circ} 04^{\prime}-120^{\circ} 23^{\prime} \mathrm{E}\right)$ is located in Shandong Province, eastern China, and is surrounding by Qingdao City, Jiaozhou City and Jiaonan City. The bay mouth is connected to the Yellow Sea in the south (Fig. 1). The size of the bay is $446 \mathrm{~km}^{2}$, yet the bay mouth is only $2.5 \mathrm{~km}$. There were more than ten inflow rivers such as Dagu River, Haibo River, Licun River and Loushan River etc., most of which are seasonal rivers whose hydrological characteristics are mainly impacted by rainfall [3-4]. The data was provided by North China Sea Environmental Monitoring Center. The survey was conducted in May, September and October 1983. Surface and 
bottom water samples in five sampling sites (H34, H35, H36, H37 and H82) were collected and measured followed by National Specification for Marine Monitoring [5]. The seasons in May, September and October could be considered as spring, summer and autumn, respectively.

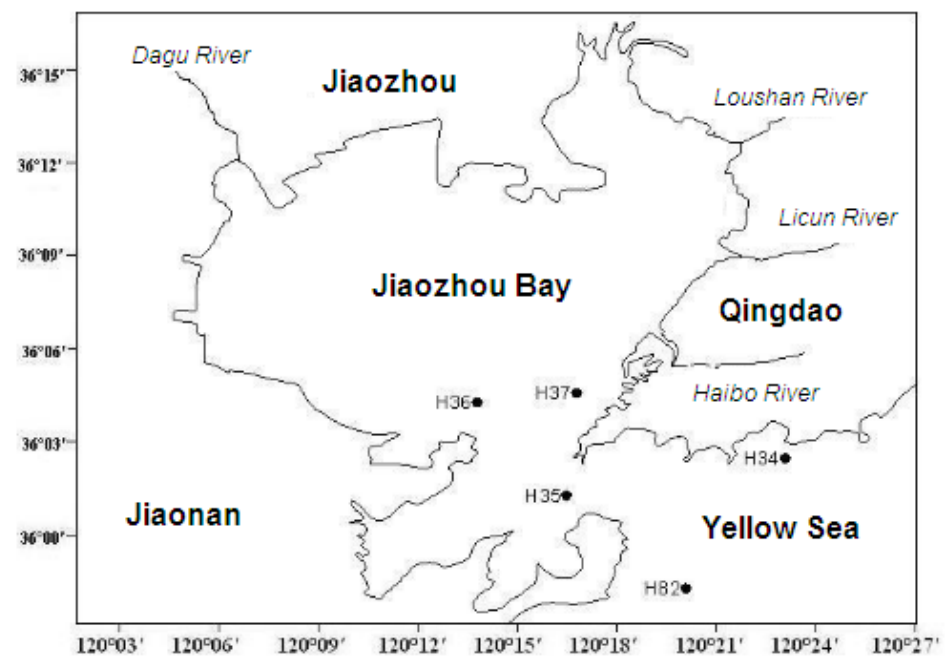

Fig. 1 Geographic location and sampling sites of Jiaozhou Bay

\section{Results}

Seasonal variations of cyanide. Cyanide contents in surface waters in May, September and October in the bay mouth of Jiaozhou Bay in 1983 were $0.03-0.08 \mu \mathrm{g} \mathrm{L} \mathrm{L}^{-1}, 0.02-0.42 \mu \mathrm{g} \mathrm{L} \mathrm{L}^{-1}$ and 0.13-0.24 $\mu \mathrm{g} \mathrm{L}^{-1}$, respectively, and the variation range was $0.02-0.42 \mu \mathrm{g} \mathrm{L}^{-1}$. While in bottom waters were $0.04-0.06 \mu \mathrm{g} \mathrm{L}^{-1}, 0.02-0.25 \mu \mathrm{g} \mathrm{L}^{-1}$ and $0.03-0.34 \mu \mathrm{g} \mathrm{L}{ }^{-1}$, respectively, with a variation range of 0.02-0.34 $\mu \mathrm{g} \mathrm{L}^{-1}$. For seasonal variations, cyanide contents in surface waters were in orders of summer $>$ autumn $>$ spring, while in bottom waters were in orders of autumn $>$ summer $>$ spring. In generally, the higher cyanide contents in surface waters, the higher cyanide contents in bottom waters.

Hozizontal distributions of cyanide. Among the five sampling Sites, Site H36 and H37 were located in the inside of the bay mouth, Site H35 was located in the middle of bay mouth, and Site H34 and H82 were located in the ouside of the bay mouth. In May, September and October, cyanide contents in both surface and bottom waters were all decreasing from the inner side to the out side. Hence, the distributions of cyanide contents in surface and bottom waters in different seasons were consistent.

Vertical variations of $\mathbf{Z n}$. In order to reveal the vertical variations of cyanide, the contents in surface waters in the fiver sampling sites were subtracted by which in bottom waters, and the positive or negative of the subtractions were listed in Table 1. For the whole year, the subtractions of cyanide contents were $-0.09-0.17 \mu \mathrm{g} \mathrm{L}^{-1}$, indicated that cyanide contents in surface and bottom waters were very closed. In May, September and OCtober, the subtractions were $-0.03-0.02 \mu \mathrm{g} \mathrm{L}^{-1}$, -0.05-0.17 $\mu \mathrm{g} \mathrm{L}^{-1}$ and $-0.10-0.02 \mu \mathrm{g} \mathrm{L}^{-1}$, respectively.

Table 1 Subtractions cyanide contents in surface waters from which in bottoms in the five sampling sites in May, September and October 1983

\begin{tabular}{|c|c|c|c|c|c|}
\hline Month & H34 & H35 & H36 & H37 & H82 \\
\hline May & Zero & Zero & Negative & Positive & Zero \\
\hline September & Zero & Negative & Positive & Positive & Zero \\
\hline October & Positive & Zero & Negative & Negative & \\
\hline
\end{tabular}




\section{Discussion}

Seasonal variations of cyanide. Cyanide contents in surface waters were in orders of summer $>$ autumn $>$ spring . The major source of cyanide in spring was river flow, whose source strength was relative low, and cyanide contents in spring in surface waters was relative low. The major cyanide source in summer was marine terminals, whose source strength was relative high, and cyanide contents in summer were relative highest. The major cyanide source in autumn was also river flow, yet the river flow discharge was less than which in spring, and there cyanide contents in spring was lowest. The cyanide contents in bottom waters were mainly determined by which in surface waters, and therefore cyanide contents in bottom waters in spring were also lowest. However, by means of vertical water's effect [6], the sedimentation and accumulation of cyanide were strong in summer due to the relative high cyanide contents in surface waters in summer, leading to the high cyanide contents in bottom waters in autumn. Hence,cyanide contents were higher in bottom waters than in surface waters. In generally, cyanide contents in bottom waters were determined by which in surface waters and the sedimentation and accumulation of cyanide.

Settling process of cyanide. By means of the vertical water's effect [6], cyanide contents in waters were changing a lot after passing through the water body. The activities of zooplankton and phytoplankton were increasing in summer, which were able to enhencing the adsorption capacity of suspended particulate matters due to the large production of colloid [4]. Hence, a large amount of cyanide was absorbed and was settling to the sea bottom under the force of gravity and current [2]. That was the horizontal settling process of cyanide. The inputs of cyanide in May and October was mainly from river flow, in which cyanide contents were lowest; while the major sources of cyanide in September was maine terminal, in which cyanide contents were lowest. The distributions of cyanide in surface and bottom waters in May, September and October were consistent, indicated that the sedimentation of cyanide were playing an dominant role in the settling process of cyanide. At vertical scale, in case of in case of low cyanide contents in waters, the losses of cyanide was very few; while in case of high cyanide contents in waters, the losses of cyanide was also very low, which were ranging from $0.00-0.08 \mu \mathrm{g} \mathrm{L}^{-1}$. Hence, the horizontal distributions of cyanide in surface and bottom waters were consistent in case of high cyanide contents, yet were closed in case of low cyanide contents.

Regional settling process of cyanide. In regional scace, in waters in the bay mouth, the subtrations of cyanide contents in surface waters from which in bottom waters were also changing along with time. Once cyanide was discharged the the bay from river flow, it was firstly reaching the surface wates, and than was settling to the bottom waters rapidly and continously, and was showing the variations of cyanide contents in surface and bottom waters. In May, cyanide contents in surface waters were relative low because the major source was river flow in which cyanide contents were very low. Hence, cyanide contents in surface waters were high than in bottom waters in the estuaries of the major river in the northeast of the bay, yet were lower in the coastal area in the south inside of the bay mouth. However, in the middle of the bay mouth and the outside of the bay mouth, the mixture of cyanide contents in waters was very well. The inputs of cyanide from river flow were beging in May, so cyanide contents in the northeast in surface waters were higher than in bottom waters, and in where far away from the estuaries of the major rivers were still lower than in bottom waters due to the transportation of cyanide had not reached the bay mouth yet. In September, cyanide were mainly sourced from marine terminal. Hence, cyanide contenrts in bottom waters were higher than in surface waters in the northeast of the bay and the southwest of the bay, yet were lower in the bay mouth. In the outside of the bay mouth, the mixture of cyanide contents in waters was very well. A relative large amount of caynide was inputted from marine terminal, leading to the high cyanide contents in surface water in northeast and the southwest of the bay. Cyanide contents in surface waters in the bay mouth were still lower than in bottom waters due to the transportation of cyanide had not reached. In October, cyanide was mainly from river flow yet the input strength was much lower than in May. Cyanide contents in surface waters in the northeast and the southwest of the bay were lower than in bottom waters. The reason was a big part of cyanide in surface waters in September was settling and accumulating in bottom waters, leading to 
the relative high cyanide contents in bottom waters in October. In the outside of the bay mouth, the mixture of cyanide contents in waters was very well, indicated that the cyanide contents were backing to the initial conditions before the inputs of cyanide. Cyanide contents were relative high in surface waters in the northeast in the outside of the bay mouth, the reason was that this region was gradually and slightly impacted by the inputs. The major sources were bringing little, moderate and large amount of cyanide to the bay anlong with time, and the contents in surface waters were changing from relative high to relative low. Mean while, waters outside of the bay mouth had not been impacted by the inputs, and the mixture of cyanide contents in waters was very well and consistent. These findings were priving the migration processes of cyanide.

Background values of cyanide. At standard scale, in the bay mouth of Jiaozhou Bay, cyanide contents in surface and bottom waters were consistent in case of few cyanide inputs. In May in the middle of the bay and the outside of the bay, the impacts of the inputs had not reached, and the mixture of cyanide contents in waters was very well. Hence, the values of cyanide contents in surface and bottom waters were $0.04-0.06 \mu \mathrm{g} \mathrm{L}^{-1}$, that were the background value of cyanide contents in May. In September in the outside of the bay, the impacts of the inputs had not reached, and the mixture of cyanide contents in waters was very well. Hence, the values of cyanide contents in surface and bottom waters were $0.02-0.22 \mu \mathrm{g} \mathrm{L} \mathrm{L}^{-1}$, that were the background value of cyanide contents in September. In October in the outside of the bay, the impacts of the inputs had not reached, and the mixture of cyanide contents in waters was very well. Hence, the values of cyanide contents in surface and bottom waters were $0.14 \mu \mathrm{g} \mathrm{L}^{-1}$, that were the background value of cyanide contents in October. In generally, the background values of cyanide in the bay were 0.02-0.22 $\mu \mathrm{g}$ $\mathrm{L}^{-1}$. These findings were important basis to the water quality standard for cyanide.

\section{Conclusion}

Cyanide contents in surface waters were in orders of summer $>$ autumn $>$ spring, while in bottom waters were in orders of autumn $>$ summer $>$ spring. At spatial scale, the horizontal distributions of cyanide in different seasons were consistent, and were decreasing from the inside of the bay mouth to the bay mouth and then the ouside of the bay mouth. At variation scale, the variation ranges of cyanide contents in boto surface and bottom waters were consistent. At vertical scale, the horizontal distributions of cyanide in surface and bottom waters were consistent in case of high cyanide contents, yet were closed in case of low cyanide contents. At region scale, the differences of cyanide contents in surface and bottom waters were determined bay the inputs of cyanide. The seasonal variations and spatial distributions of cyanide were revealing the horizontal water's effect and vertical water's effect. The background values of cyanide in the bay could be defined as $0.02-0.22 \mu \mathrm{g} \mathrm{L}{ }^{-1}$.

\section{Acknowledgement}

This research was sponsored by Doctoral Degree Construction Library of Guizhou Nationalities University, Education Ministry's New Century Excellent Talents Supporting Plan (NCET-12-0659), the China National Natural Science Foundation (31560107), Major Project of Science and Technology of Guizhou Provincial ([2004]6007-01), Guizhou R\&D Program for Social Development ([2014] 3036) and Research Projects of Guizhou Nationalities University ([2014]02), Research Projects of Guizhou Province Ministry of Education (KY [2014] 266), Research Projects of Guizhou Province Ministry of Science and Technology (LH [2014] 7376).

\section{Reference}

[1] Yang DF, He XH, Gao J, et al.: Materials, Environmental and Biological Engineering. Vol. (2015), p. 40-43.

[2] Yang DF, He XG, Gao J, et al.: Advanced Materials Research, Vol.1092-1093 (2015), p. 992-995. 
[3] Yang DF, Chen Y, Gao ZH, et al.:Chinese Journal of Oceanology Limnology, Vol. 23(2005), p. 72-90.

[4] Yang DF, Wang F, Gao ZH, et al.: Maine Science, Vol. 28(2004): 71-74. (in Chinese with English abstract)

[5] State Ocean Administration. The specification for marine monitoring: Beijing, Ocean Precess, (1991).

[6] Yang DF, Wang FY, He HZ, et al.:Proceedings of the 2015 international symposium on computers and informatics, (2015), p. 2655-2660. 